\section{Increased bronchoalveolar lavage fluid tin content in stannosis}

\author{
Alan Altraja, ${ }^{1,2}$ Kaidi Nigol, ${ }^{2}$ Siiri Altraja, ${ }^{3}$ \\ Anu Viitak ${ }^{4}$ \\ 'Department of Pulmonary Medicine, \\ University of Tartu; ${ }^{2}$ Tartu University \\ Hospital, Lung Clinic, Tartu; \\ ${ }^{3}$ Institute of General and Molecular \\ Pathology, University of Tartu; \\ ${ }^{4}$ Tallinn University of Technology, Faculty \\ of Science, Department of Chemistry, \\ Tallinn, Estonia
}

\section{Abstract}

Stannosis is a rare non-fibrotic pneumoconiosis that follows the chronic inhalation of tin particles. Apart from occupational history and radiographic findings, no diagnostic criteria exist for stannosis. Therefore, analysis of bronchoalveolar lavage fluid (BALF) to support stannosis might be of significant value. We present a case of a 74-year-old male patient, who developed progressive dyspnea and dry cough 35 years after working full-time as a tinner for 17 years. His post-bronchodilator forced vital capacity and forced expiratory volume in one second were $111 \%$ and $108 \%$ predicted, respectively, accompanied by a disproportionately low diffusing capacity of the lung (34.4\% predicted). Contents of tin, lead and copper were measured in both the BALF and the systemic circulation by electrothermal atomic and flame absorption spectrometry. The patient had a 38.5-, 48.5-, 88- and 85fold higher BALF concentration of tin than did four male individuals (controls) without stannosis or an exposure to other heavy metals (crude figures and standardized for total protein, albumin, and potassium contents, respectively). Moreover, there was no difference in the BALF concentrations of lead and copper, or any of the heavy metals in the peripheral blood stream between the patient and the controls. The relative coefficient of excretion of 24.9 for tin in the patient and of $<1$ both for tin in the controls and for other metals in the patient, as well as for all metals in the controls refers to the deposition of tin locally into the lungs of the patient via chronic inhalation. This case study indicates that weighed measurement of tin in the BALF could provide significant support to the clinical diagnosis of stannosis.

\section{Introduction}

Stannosis is a rare form of non-fibrotic pneumoconiosis that results from the deposition of tin in the lung tissue after inhalation of dusts or fumes containing tin or tin dioxide particles. ${ }^{1,2}$ Most often, stannosis develops in workers occupied in the tinning or tin plate industries. ${ }^{3,4}$ The literature published in English or having at least an abstract in English, demonstrates that our present knowledge on stannosis is mainly based on case reports..$^{1-3,5,6}$ No diagnostic criteria exist for stannosis other than the presence of a typical history of professional exposure to tin or tin dioxide and certain radiographic findings that usually include nodular opacities of 3 to $5 \mathrm{~mm}$ with no significant pulmonary fibrosis.,6,7 However, there is no clear correlation between the time and massiveness of exposure to tin and the radiographic changes, ${ }^{3,8}$ probably because there is typically no remarkable lung tissue reaction to the deposited tin or tin compounds. ${ }^{1,9,10}$ Moreover, in stannosis, there is commonly a mismatch between widespread radiographic changes in the lungs and wellpreserved spirometric lung function test results, again, most likely due to the lack of inflammatory and fibrotic reactions. Therefore, the analysis of bronchoalveolar lavage fluid (BALF) to support the diagnosis of stannosis, particularly as an occupational disease, by at least elucidating a marked heightening of tin content in the lung, might be of practical value.

\section{Case Report}

A 74-year-old Caucasian male was referred to our clinic with a one-year history of dry cough and progressive dyspnea. The onset of his respiratory symptoms started 35 years after he terminated a 17-year long occupational career as a full-time tinner of large copper milk reservoirs in a dairy in Southern Estonia. In the process of tinning of the milk tanks by the patient, molten tin was made instantly on site from thin tin powder (grey tin) using a gas torch. The final spreading of the tin to the inside of the tanks was done with a cork bat. As a flux, ammonium chloride and zinc chloride were used, both are known as producers of dense fumes to facilitate aerosolizing of tin and thereby causing stannosis. ${ }^{3}$ For tinning of the inside of the milk tanks, the patient had to work within the tank in conditions of no exhaust ventilation. Moreover, the patient did not use any individual measures to protect his respiratory tract. Further history revealed that the patient was a former smoker (20 packyears, quitted 3 years ago).
Correspondence: Alan Altraja, Department of Pulmonary Medicine, University of Tartu, 8 Puusepa Street, 51014 Tartu, Estonia. Tel. +372.7.318901-Fax: +372.7.318905

E-mail: alan@kliinikum.ee

Key words: stannosis, bronhcoalveolar lavage, tin.

Acknowledgements: the skillful assistance of Mr. Aivar Orav with performing analyses on BALF is acknowledged.

Contributions: AA, report designing, study subject selection, bronchoscopies and bronchoalveolar lavages performing, biofluids analysis, data analysis and interpretation, manuscript drafting; $\mathrm{KN}$, patient and control selection, clinical characterization of the study subjects, data analysis and interpretation; SA, bronchoalveolar lavage fluid samples for analyses preparation, bronchoalveolar lavage fluid protein analysis, data interpretation, manuscript drafting and critical revision; $\mathrm{AV}$, heavy metals: methods of analysis in the biofluids suggestion, analyses performing, data interpretation, manuscript writing.

Conflict of interests: the authors declare that they have no conflict of interests.

Received for publication: 31 October 2011. Revision received: 7 March 2011.

Accepted for publication: 8 March 2011.

This work is licensed under a Creative Commons Attribution NonCommercial 3.0 License (CC BYNC 3.0).

(C) Copyright A. Altraja et al., 2012

Licensee PAGEPress, Italy

Chest Disease Reports 2012; 2:e8

doi:10.4081/cdr.2012.e8

Post-bronchodilator values of forced vital capacity [FVC, $3.14 \mathrm{~L}$ (111\% predicted)] and forced expiratory volume in one second $\left[\mathrm{FEV}_{1}\right.$ 2.43 L (108\% predicted)] were normal, but were accompanied by a disproportionately low diffusing capacity of the lung (DLCO) 2.4 mmol $\times \mathrm{min}^{-1} \times \mathrm{mmHg}^{-1}$ (34.4\% predicted) and

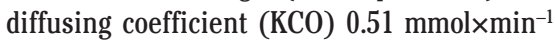
$\times \mathrm{mmHg}^{-1} \times \mathrm{L}^{-1} \quad(42.4 \%$ predicted $)$. The 6 minute walk distance was $460 \mathrm{~m}$ with a drop in $\mathrm{SpO}_{2}$ to $75 \%$. Slight pulmonary hypertension was present (systolic pulmonary artery pressure of $46 \mathrm{mmHg}$, assessed by echocardiography). Alternative major interstitial lung diseases or pulmonary manifestations of systemic diseases including vasculitis, were excluded by chest high-resolution computed tomography (HRCT) (Figure 1) and appropriate panels of serological tests.

To evaluate the indices obtained for this patient, four age-matched non-smoking Caucasian male individuals with no history of either exposure to any heavy metal, with near- 
normal lung function and radiographic appearance of the lungs not characteristic of a pneumoconiosis and free of respiratory infections were included from our centre as comparators. All patients underwent the procedures described in this report routinely, as deemed clinically indicated by the responsible physician. After obtaining written informed consent, fiberoptic bronchoscopy was performed in the patient, as well as in the control individuals to check for possible pathological signs in the central bronchi, as well as to assess the disease markers, particularly the contents of heavy metals, in the BALF. Bronchoalveolar lavage was performed in concordance with international standards ${ }^{11}$ by instilling a total of $200 \mathrm{~mL}$ saline, divided into $20-\mathrm{mL}$ aliquots, to the $4^{\text {th }}$ of $5^{\text {th }}$ segment in the right middle lobe. An aspirated fluid recovery of at least 80\% (160 $\mathrm{mL}$ ) was obtained in all participants. The BALF cellular components were assessed using both cytospin preparations and sections of cellblocks created from the pellet of centrifuged BALF. In the patient, no ciliated bronchial epithelial cells and no eosinophils were detectable in the BALF displaying $90.5 \%$ alveolar macrophages. The proportions of neutrophils and lymphocytes in the BALF of the patient with stannosis were $2 \%$ and $7.5 \%$, respectively. In the control individuals, their BALF displayed normal cellularity, and the dif-

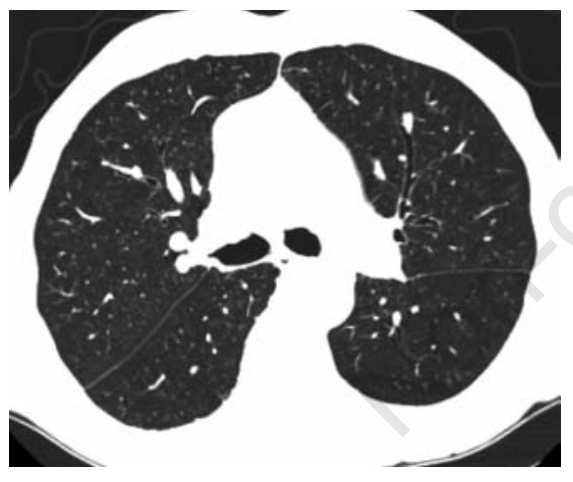

Figure 1. High-resolution computed tomography scan of a 74-year-old male patient with stannosis, who presented with progressive dyspnea and dry cough, which developed 35 year after working full-time as a tinner of large milk tanks for 17 years. Only slight interlobular thickening and paraseptal shading is seen in some sites of the lung periphery. Normal spirometric lung function was accompanied by disproportionately low diffusing capacity of the lung $(34.4 \%$ predicted). ferential cell counts were within the normal ranges. Due to the expected proceduredependent inter-individual variability in the dilutions of all compounds in BALF, the concentrations of albumin and potassium were used to standardize the BALF heavy metal contents. In parallel, venous blood samples were drawn from each participant to perform comparative analyses for the heavy metals, as well as for total protein, albumin and potassium content. Measurement of the contents of the total protein, albumin and potassium in both the BALF and serum was performed according to routine standards used at the clinical laboratory; however, to analyse the BALF, concentration of the samples by means of vacuum concentration was necessary in all cases.

For the analyses of heavy metal contents, 2 $\mathrm{mL}$ of the BALF and the whole blood was mineralized by $5 \mathrm{~mL}$ of concentrated nitric acid and $2 \mathrm{~mL}$ of concentrated hydrogen peroxide in teflon bombs in a microwave oven (Anton Paar Multiwave 3000, Graz, Austria) at temperatures up to $180^{\circ} \mathrm{C}$ for $30 \mathrm{~min}$. After cooling down, the solution in the bombs was transferred to $15 \mathrm{~mL}$ Milli- $\mathrm{Q}$ water in volumetric flasks with for determination of the total concentration of elements. The contents of tin and lead were analyzed with use of electrothermal atomic absorption spectrometry (ETAAS) and that of copper with flame (F)-AAS. For ETAAS and FAAS, Spectra AA $220 \mathrm{Z}$ and 220F atomic absorption spectrometers (Varian, Mulgrave, Australia), equipped with a side-heated GTA$110 \mathrm{Z}$ graphite atomizer, Zeeman-effect background correction, an integrated auto-sampler with a platform and graphite tubes of pyrolytic graphite, were used. The total volume of the sample for the analysis of tin and lead was 30 $\mu \mathrm{L}$, containing $10 \mu \mathrm{L}$ of colloidal palladium modifier $(1 \mathrm{mg} / \mathrm{mL})$. The measurement wavelengths were $286.3 \mathrm{~nm}$ for tin, $283.3 \mathrm{~nm}$ for lead and $324.8 \mathrm{~nm}$ for copper. Accuracy was checked using standard reference materials (Seronorm Trace Elements Whole Blood Level 1, MR4206 and Level 3, OK 0337). The BALF of the patient with clinically suspected stannosis, contained a 38.5-, 48.5-, 88-, and 85-fold higher concentration of tin compared to the mean tin concentration found in the four control individuals (crude results and standardized for the total protein, albumin, and potassium content, respectively, Table 1). By comparison, no such a difference was present for the BALF concentrations of either lead or copper. Moreover, there were no differences for the contents of these metals in peripheral blood. Notably, the BALF-to-blood content ratio of tin was more than six in the stannosis patient (even more than 14, if the albumin-standard-

Table 1. Crude and standardized contents of tin, lead, and copper in the bronchoalveolar lavage fluid and peripheral blood of a patient with stannosis compared with that in four non-pneumoconiotic individuals with no history of exposure to heavy metals (controls mean values \pm SEM are indicated where appropriate). SEM, standard error of mean.

\begin{tabular}{|c|c|c|c|}
\hline . & $\operatorname{Tin}(\mu g / L)$ & Lead ( $\mu \mathrm{g} / \mathrm{L})$ & Copper (mg/L) \\
\hline $\begin{array}{l}\text { BALF, crude measurements } \\
\text { Patient } \\
\text { Controls } \\
\text { Patient/control ratio }\end{array}$ & $\begin{array}{c}600.00 \\
15.60 \pm 7.76 \\
38.46\end{array}$ & $\begin{array}{c}1.60 \\
3.56 \pm 1.24 \\
0.45\end{array}$ & $\begin{array}{c}0.08 \\
0.06 \pm 0.03 \\
1.37\end{array}$ \\
\hline $\begin{array}{l}\text { BALF, standardized for total protein } \\
\text { Patient } \\
\text { Controls } \\
\text { Patient/control ratio } \\
\end{array}$ & $\begin{array}{c}990.00 \\
20.42 \pm 9.44 \\
48.47\end{array}$ & $\begin{array}{c}2.64 \\
3.69 \pm 1.08 \\
0.71\end{array}$ & $\begin{array}{c}0.13 \\
0.11 \pm 0.08 \\
1.17\end{array}$ \\
\hline $\begin{array}{l}\text { BALF, standardized for albumin } \\
\text { Patient } \\
\text { Controls } \\
\text { Patient/control ratio }\end{array}$ & $\begin{array}{c}1404.10 \\
15.96 \pm 6.96 \\
87.96\end{array}$ & $\begin{array}{c}3.74 \\
3.20 \pm 0.87 \\
1.17\end{array}$ & $\begin{array}{l}0.19 \\
0.08 \pm 0.05 \\
2.42\end{array}$ \\
\hline $\begin{array}{l}\text { BALF, standardized for potassium } \\
\text { Patient } \\
\text { Controls } \\
\text { Patient/control ratio }\end{array}$ & $\begin{array}{c}1248.00 \\
14.69 \pm 4.71 \\
84.95 \\
\end{array}$ & $\begin{array}{c}3.33 \\
5.13 \pm 1.98 \\
0.65\end{array}$ & $\begin{array}{c}0.17 \\
0.09 \pm 0.06 \\
1.91\end{array}$ \\
\hline $\begin{array}{l}\text { Peripheral blood } \\
\text { Patient } \\
\text { Controls } \\
\text { Patient/control ratio }\end{array}$ & $\begin{array}{l}95.00 \\
23.00 \pm 4.98 \\
4.13\end{array}$ & $\begin{array}{c}52.0 \\
23.3 \pm 6.69 \\
2.23\end{array}$ & $\begin{array}{c}0.79 \\
0.83 \pm 0.08 \\
0.95\end{array}$ \\
\hline $\begin{array}{l}\text { BALF (crude)/peripheral blood ratio } \\
\text { Patient } \\
\text { Controls } \\
\text { Patient/control ratio }\end{array}$ & $\begin{array}{l}6.32 \\
0.58 \pm 0.17 \\
10.86\end{array}$ & $\begin{array}{l}0.03 \\
0.30 \pm 0.18 \\
0.10\end{array}$ & $\begin{array}{c}0.10 \\
0.08 \pm 0.04 \\
1.26\end{array}$ \\
\hline
\end{tabular}

BALF, bronchoalveolar lavage fluid. 
ized content of tin in the BALF was used in the calculation), but was below one in the controls, as it was markedly below one in cases of the other metals both in the patient, as well as in the controls (Table 1). In order to distinguish between possible excretion of the heavy metals from the bloodstream into the lungs and the deposition of these metals locally into the lungs via chronic inhalation, the relative coefficients of excretion (RCEs) was calculated using the BALF and serum concentrations of the metals and albumin according to the formula RCE $=\left(\left[\right.\right.$ metal $\left._{\text {BALF }}\right] /\left[\right.$ metal $\left.\left._{\text {serum }}\right]\right) /([$ albu$\left.\left.\min _{\mathrm{BALF}}\right] /\left[\operatorname{albumin}_{\text {serum }}\right]\right)$, i.e. a modification of a method previously recommended for judging upon the origin of immunolgobulins in the BALF $^{12}$ was applied. In particular, in the calculations, the serum albumin content was expressed in $\mathrm{g} / \mathrm{L}$, whereas the rest of the concentration units in this formula remained as $\mathrm{mg} / \mathrm{L}$. With the BALF and serum albumin concentrations of $12.2 \mathrm{mg} / \mathrm{L}$ and $48.0 \mathrm{~g} / \mathrm{L}$, respectively in the patient and $34.0 \pm 9.8 \mathrm{mg} / \mathrm{L}$ and $43.0 \pm 2.0 \mathrm{~g} / \mathrm{L}$, respectively in the controls (mean \pm SEM), the respective RCE values for tin, lead and copper were 24.85, 0.12 and 0.40 in the patient and $0.86,0.19$ and 0.09 in the controls. During the follow-up, on the contrary to that what was expected, the patient progressively deteriorated with steadily worsening hypoxemia without a carbon dioxide retention and later died as a result of respiratory failure 2 years after the diagnosis.

\section{Discussion}

Although bronchoalveolar lavage has been applied as a tool in the diagnosis of other heavy metal diseases, ${ }^{13}$ this is the first report to indicate a frank heightening of the tin content in the BALF of a stannosis patient with a prolonged occupational exposure to inhaled tin. Although no perfect statistical analyses can be made between the data from a single patient and those from the control group, the 38.5-to-88-fold greater content as detected in the current patient could be deemed as a major heightening. Nevertheless, if the four BALF tin concentrations of the patient (crude and standardized for the total protein, albumin and potassium contents, Table 1) were put togeth- er and compared with those from the control individuals, small groups with normally distributed data (by the Shapiro-Wilk test) were noted showing a significantly increased tin content in the patient's BALF compared to that in the controls $(\mathrm{P}=0.0095$, Student's 2-tailed ttest). No such a difference was found for the BALF contents of lead and copper, indicating that the patient, as well as the control individuals, had been equally subjected to an environmental exposure to these heavy metals. Since a possibility exists that the heavy metals were secreted from the circulation into the lungs, the RCE values were calculated according to a modification of a method previously recommended to investigate the origin of immunoglobulins in the BALF. ${ }^{12}$ RCE values of almost 25 for tin in the patient and below 1 both for tin in the control group and for other metals in the patient, as well as for all metals among the controls convincingly speak in favour of the deposition of tin locally into the lungs of the patient via chronic inhalation ${ }^{12}$ rather than getting into the lung parenchyma by chance or with blood or lymph circulation.

It this patient, there were only subtle radiological changes in the lungs and well-preserved spirometric lung function. The former finding is somehow in line with the known absence of an unambiguous relationship between the exposure to tin and the radiographic changes. ${ }^{3,8}$ Normal spirometric lung function has also been reported in patients with stannosis, even in those, who have remarkable derangements on chest X-rays and chest CT scans. ${ }^{2}$ Unlike spirometry data, the values of the diffusing capacity of the lungs have often been missing from the reports on patients with stannosis. However, according to the example of the current case, just the very low diffusing capacity of the lung could be responsible for the rapid deterioration and death as a result of progressive respiratory failure. In conclusion, although the critical threshold concentration of tin in the BALF remains to be determined, this case study demonstrates how a markedly elevated BALF tin content can be documented in a patient with stannosis. Thus, weighed measurement of tin in BALF could provide a significant benefit in verifying the diagnosis of stannosis by adding a valuable supplement to the relevant occupational history, clinical signs and radiographic changes.

\section{References}

1. Sluis-Cremer GK, Thomas RG, Goldstein B, Solomon A. Stannosis. A report of 2 cases. S Afr Med J 1989;75:124-6.

2. Yilmaz A, Gocmen Ocal S, Doruk S, Acu B. Is tin fume exposure benign or not? Two case reports. Tuberk Toraks 2009;57:422-6.

3. Cole CW, Davies JV, Kipling MD, Ritchie GL. Stannosis in hearth tinners. Br J Ind Med 1964;21:235-41.

4. Robertson AJ, Rivers D, Nagelschmidt G, Duncumb P. Stannosis: benign pneumoconiosis due to tin dioxide. Lancet 1961;1: 1089-93.

5. Spencer GE, Wycoff WC. Benign tin oxide pneumoconiosis. AMA Arch Ind Health 1954;10:295-7.

6. Marchiori E, Souza AS Jr, Franquet T, Muller NL. Diffuse high-attenuation pulmonary abnormalities: a pattern-oriented diagnostic approach on high-resolution CT. AJR Am J Roentgenol 2005;184:273-82.

7. Chong S, Lee KS, Chung MJ, et al. Pneu moconiosis: comparison of imaging and pathologic findings. Radiographics 2006; 26:59-77.

8. Robertson AJ, Whitaker PH. Radiological changes in pneumoconiosis due to tin oxide. J Fac Radiol 1955;6:224-33.

9. Chan ED, Morales DV, Welsh $\mathrm{CH}$, et al. Calcium deposition with or without bone formation in the lung. Am J Respir Crit Care Med 2002;165:1654-69.

10. Brown K, Mund DF, Aberle DR, et al. Intrathoracic calcifications: radiographic features and differential diagnoses. Radiographics 1994;14:1247-61.

11. Technical recommendations and guidelines for bronchoalveolar lavage (BAL). Report of the European Society of Pneumology Task Group. Eur Respir J 1989; 2:561-85.

12. Merrill WW, Out TA. Measurement of immunoglobulins in bronchoalveolar lavage fluid. Eur Respir Rev 1999;9:70-5.

13. Forni A. Bronchoalveolar lavage in the diagnosis of hard metal disease. Sci Total Environ 1994;150:69-76. 